\title{
LIVESTOCK PEST TRAINING MANUAL
}

\section{STATE DOCUMENTS COLLECTIO:I}
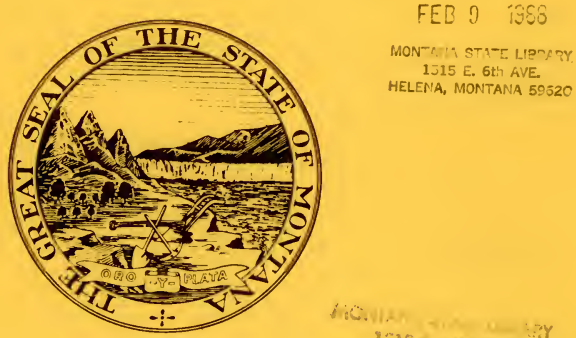

\author{
STATE OF MONTANA \\ DEPARTMENT OF AGRICULTURE \\ HELENA, MONTANA \\ JANUARY, 1981 \\ PLEASE RETURN
}


NAY 61989

1i. $2: 2012$ 
This guide is designed to provide the commercial and private applicator detailed information concerning the recognition and biology of the major pests attacking livestock and poultry in Montana. Additionally, specific approaches to treatment and control of these pests are outlined. Chemical recommendations listed in this guide reflect the best information available at the time of printing. No endorsement of named products is intended nor is it implied that products not listed are less effective. The applicator is strongly urged to confirm the registration status of recommended products prior to purchase by consulting the Environmental Management Jivision, Montana Department of Agriculture.

To simplify information, trade named products and equipment have been mentioned. No endorsement is intended, nor is criticism implied of similar products or equipment which are not mentioned.

We wish to acknowledge the help of personnel of the Environmental Management Division, Montana Department of Agriculture, in preparing this manual. 
A. General Sanitation and Farm Management. . 1

B. Chemical Methods . . . . . . . . 2

C. Application Methods . . . . . . . 3

D. Chemical Application Safety . . . . . 6

CHAPTER II. INSECTS AND RELATED PESTS OF LIVESTOCK. • . . 9

A. External Parasites . . . . . . . 9

B. Internal Parasites. . . . . . . . 29

CHAPTER III. INSECTS AND RELATED PESTS OF POULTRY. • • . 32

A. Control of Poultry Pests Through Management. . . . . . . . . 32

B. Representative Poultry Pests and Their Control . . . . . . . . 34

Table 1. Selected Characteristics of Insecticides Listed In this Publication. . . . . . . . . . 8 


\section{CHAPTER I}

TREATMENT MEASURES FOR LIVESTOCK AND POULTRY PESTS

\section{General Sanitation and Farm Management}

Elimination of insect breeding sites and the prevention of conditions or practices that predispose animals to attack should form the basis of any livestock pest management program. Many insect pests such as biting and nuisance flies develop in accumulations of manure, wet straw, spilled feeds, carrion and drainage water. Sound farm sanitation practices such as spreading of manure, removal of wet straw from pens and corrals, prompt clean up of feed spills, and filling in of low spots around buildings and pens where water might accumulate can prevent biting and nuisance fly buildup.

Certain management practices can also be effective in controlling buildup of certain pests. Providing a dark shed or similar shelter so stock can escape fly activity during the day is one example. Groves of trees in pastures also provide shelter. Raising certain breeds of animals less susceptible to a particular pest may be advantageous in perennially high infestation areas. General animal health and nutrition can affect the susceptibility of livestock and poultry. Animals in good health are better able to resist certain pests, consequently pest populations are held at low levels. 
Chemicals for treatment of livestock and poultry pests are available in the form of dusts, liquids to be diluted for use in dipping vats or sprayers, or liquids pre-mixed and ready to use from the container. Some insecticides are available in the form of feed additives, gels, oil solutions or dusts for use on backrubbers or in dust bags. The choice of insecticide formulation will be determined in large part by the nature of the treatment situation. Beef cattle held on the range may not lend themselves to the same treatment methods as cattle held in a feed lot situation. Time of year and pest biology are also factors to be considered when selecting the appropriate formulation.

Preparation of the correct concentration of insecticide is essential for successful control of insect pests of livestock. Errors in determining the quantity of the insecticide concentrate that must be mixed with water or oil can result in the use of excess toxicant. This practice is costly and may lead to residue or toxicity problems. The use of too little insecticide in a spray mixture will not provide insect control and is a waste of insecticide, time and labor.

In practically all livestock insect control, the concentration of insecticide in a spray or dip mixture is expressed as percent. Most of the insecticides that one can purchase for spraying or dipping are wettable powders or emusifiable concentrates. These must be diluted with water to the recommended concentration before use. The determination of how 
much wettable powder or emulsifiable concentrate needed to prepare a certain volume of dilute spray or dip liquid is outlined in the Montana Department of Agriculture Basic Pesticide Equipment Manual.

Application Methods

\section{High Pressure Spray}

Application of insecticides under pressure (250-350 psi) remains a popular method of treating livestock. Spraying is applicable where animals can be held in a pen and worked back and forth to assure adequate coverage with the chemical. The high pressure is essential when applying systemic insecticides since the skin (not the hair) must be thoroughly wetted. It is important that the correct chemical dilution and sprayer calibration procedures are followed. Refer to the Montana Department of Agriculture Basic Pesticide Equipment Manual.

\section{$\underline{\text { Dips }}$}

Submersion of livestock in a dipping vat is an excellent method of obtaining thorough coverage. Several chemicals are formulated to be used in dipping operations. Management of vat dipping operations requires close adherence to directions. Correct concentration of the chemical in the vat must be maintained. The wrong concentration could result in the following:

1) treated animals could experience illness or even death,

2) all parasites may not be killed,

3) repeated use of inadequate concentrations could result in development of resistant parasite populations. 
The following guidelines should be considered in all dipping operations :

$\underline{\text { DO }}$

- Inspect all animals prior to treatment.

- Allow animals to cool off, rest and drink their fill of water before treatment.

- Remove mud, filth, or heavy dust accumulations.

- Inspect vat facilities for servicability.

- Properly mix the pesticide and diluent before using vat.

- Completely submerge livestock including the head.

$\underline{\text { DON'T }}$

- Dip rain soaked animals.

- Allow dams to nurse young until the dip has dripped off the udder and teats are dry.

- Allow drip to contaminate water sources, feed, or the barnyard.

- Dispose of excess vat drippings in areas where water could be contaminated.

\section{Pour-ons}

Many systemic insecticides are formulated as liquid pourons. This method is a quick and effective way of applying the material to a specific localized area of the animal. The solution, either an oil or emulsion, is poured directly from a calibrated dipper along the back of the animal at a rate preventing runoff.

\section{Spot-on}

Like the pour-on method, the spot-on technique allows for the direct application of a measured amount of chemical to the 
back of the animal. The spot-on method utilizes a specially designed gun for application. The rate is determined by the size of the animal and obtained by adjusting the applicator gun.

\section{Backrubber}

Oil solution insecticides can be applied with a backrubber. The backrubber consists of a cable around which burlap or a similar absorbitive material is wrapped. The cable is suspended between two posts about 20 feet apart and allowed to sag about $1 \frac{1}{2}-2$ feet above the ground. The insecticide mixed with No. 2 diesel fuel at the label rate is applied to the burlap. The backrubber is located near an area where cattle loaf, a water source or salt lick.

\section{Dust Bag}

Horn flies, particularly, can be effectively controlled by installation of a dust bag. The dust bag is merely a heavy weight burlap bag filled with a registered insecticide dust and suspended in areas where cattle are forced to pass. The chemical is applied as the animal brushes against the bag.

\section{Feed Additives}

Some systemic insecticides are formulated as additives that must be consumed at certain rates in order to be effective against such pests as cattle grubs. They are available in three forms: granular feed mix, mineral granules and mineral block. Application should follow label directions closely. 


\section{Hand Sprayers and Dusters}

These devices are useful in applying small amounts of chemicals to animals or treating animal premises. Particular attention must be paid to the applicator directions as well as the product label to assure proper application.

\section{Misters and Foggers}

Treatment of buildings, pens and yards for nuisance flies is often done most efficiently with a mister or fogger. Some insecticides are formulated especially for this type of application. Refer to the product label for specific mixing and application instructions.

\section{Chemical Application Safety}

The best guide to correct use of a chemical pesticide is the product label. The label contains information regarding: 1) amount and type of active ingredient; 2) directions for mixing and application; 3) environmental hazards; 4) use precautions; 5) first aid information; 6) storage and disposal directions.

Listed next are guidelines that will help insure safe and effective pesticide application.

1) If you have a question concerning the need for or use of a product to a particular crop or animal, consult your nearest Cooperative Extension Specialist or the Montana Department of Agriculture.

2) Do not apply a pesticide for a use not listed clearly on the product label. 
3) Do not apply a pesticide at a rate less than or greater than the recommended rate on the label. Lesser rates may be ineffective; excessive rates can result in harm to the animal and are expensive.

4) Make sure your sprayer or application equipment is properly calibrated. See the Basic Pesticide Equipment Manual.

5) Wear protective clothing as recommended on the label.

6) Do not apply sprays at temperatures in excess of $85^{\circ} \mathrm{F}$. or under windy conditions. Be aware of possible spray drift and minimize it.

7) Store pesticides in their original containers in a locked storage area.

8) In the case of accidental poisoning, follow first aid measures listed on the label, contact a physician or the nearest poison control center for assistance. 
Table 1. SRLECTED CHARACTERISTICS OF INSECTICIDFS LISTFD IN TIIS PURLICATLON ${ }^{1}$

\begin{tabular}{|c|c|c|c|c|c|c|c|}
\hline Insecticide & Trade Name & Proclucer & Chusitical Class & $\begin{array}{l}\text { Acint: } \\
\text { Orin } \\
\text { LDSo }\end{array}$ & $\begin{array}{c}\text { Thxicily }{ }^{2} \\
\text { Dormol } \\
\text { ID50 }\end{array}$ & $\begin{array}{l}\text { Relative Toxicity } \\
\text { To Thmans }\end{array}$ & $\begin{array}{l}\text { Signa! w: } \\
\text { Or Jible! }\end{array}$ \\
\hline carbaryl & Sevin & Union Carbirle Corp. & carbomate & 500 & 2000 & $\ln w$ & CAUTION \\
\hline chloropyrifos & Dursiban 44 & Dow $C^{\prime}$ al Corpany & Druanic phosphate & 163 & 2000 & molerate & WRRNINK; \\
\hline coumaphos & $\mathrm{Co}-\mathrm{PaI}$ & Cuttor iaboratories & Organic phosphate & $56-230$ & 860 & moderato & WARNTNS \\
\hline crotoxyphos & $\begin{array}{l}\text { Ciodrin, } \\
\text { Ciovap } 3\end{array}$ & Shell Chemical co. & Orcanic phosphate & 125 & 385 & moderate & WARNING; \\
\hline crufomvte & Puelene & Dow Crumical Conpary & Organic: phosphate & 770 & 2000 & $10 w$ & CNIIION \\
\hline diazinon & Diazirxon & Ciba-sciry Comp. & Orannic phosphate & 300 & 4000 & moxierite & INARVII: \\
\hline dichlorvos & $\begin{array}{l}\text { Deve, } \\
\text { Vapona }\end{array}$ & Shell Cohrnica] Co. & Orquanic phosphate & 56 & $\ln 7$ & moierate & WARENTN: \\
\hline dimethoate & $\begin{array}{l}\text { Cygon, } \\
\text { De-Fend }\end{array}$ & Anrican Cyanamid Co. & Oryanic phosphate & 320 & 700 & moderatc & IVIPONIN: \\
\hline dioxathion & Delnav & lercules, Inc. & Organic phosphate & 43 & 107 & high & DNMTIR \\
\hline fenthion & $\begin{array}{l}\text { Lysoff, } \\
\text { Spotton, } \\
\text { Tiguvon }\end{array}$ & Mbay Chamical Co. & Organic phosphate & 250 & 330 & moxlerate & WARNING \\
\hline farphur & $\begin{array}{l}\text { Bo-Äna, } \\
\text { Warbex }\end{array}$ & Anerican Cyanamid $\infty$. & Organic phosphate & $36-62$ & $1460-5090$ & high & DNNFER \\
\hline lindane & - & Hooker Chemical & $\begin{array}{l}\text { Chlorinated hyciro- } \\
\text { carbon }\end{array}$ & $88-125$ & 1000 & moderate & WIRNITI \\
\hline nalathion & Cythion & Anerican Cyanamid Co. & Organic phosphlate & 1375 & 4100 & low & CNTUION \\
\hline methoxychlor & Marlate & Dupont & $\begin{array}{l}\text { Chlorinatod hyciro- } \\
\text { carbon }\end{array}$ & 6000 & - & $1 \mathrm{Cw}$ & CNTUION \\
\hline naled & Dibran & Chevron Chemical $\mathrm{Co}$. & Organic phosphate & 430 & 1100 & low & CAUTION \\
\hline phosmet & Prolate & Stinurfize Chmical Co. & Orcanic phosphate & $3 n n$ & 3160 & mrxkrate & W/RNII: \\
\hline pyrethrins & $\cdots$ & FMC Corporation & Botanical & 200 & 1800 & low & CAUTION \\
\hline ronnel & $\begin{array}{l}\text { Korlan } \\
\text { Trolcne }\end{array}$ & Dow Chemical Oampany & Organic phnsphate & 1740 & 1000 & low & CAUTIRN \\
\hline stirofos & $\begin{array}{l}\text { Rabon } \\
\text { Ravap } 4\end{array}$ & Shell Chenical Co. & Orqanic phosphate & 4000 & 5000 & $10 w$ & CAUTION \\
\hline toxaphene & toxaphenc & Hercules, Inc. & $\begin{array}{l}\text { Chlorinatod hydro- } \\
\text { carbon }\end{array}$ & 69 & - & moderate & WNPNIM, \\
\hline trichlorfon & $\begin{array}{l}\text { Dipterex } \\
\text { Neguvon }\end{array}$ & Mobay Chanical Co. & Organic phosphate & 450 & 5000 & low & CNITION \\
\hline
\end{tabular}

1 This table adapted from Univorsity of Maryland, Cooperative Fxtension Bul Letin \#25\%. Prvised 1979-80.

2 LD50 is the dose of a prosticide which would kill half of a large nutber of test animals if eaten or absorbed through the skin. These values are reconded in milligrams of pesticide per kilogram of body weight of test animals. The lower the LD50 value the more poisonous the pesticide. Oral LD50 usually detcrmined on rats or mice; dermal iD50 usually determined on rabbits.

3 Ciovap is a mixture of crotoxyphos and dichlorvos

4 Ravap is a mixture of stirofos and dichlorvos 
INSECTS AND RELATED PESTS OF LIVESTOCK

Insects, mites and ticks can seriously reduce the production, efficiency and quality of livestock and poultry. Animal losses due to livestock pests in the U. S. have been estimated at over 800 million dollars.

The most important pests of livestock and poultry are animal parasites. They can be divided into two groups:

External parasites (living on the outside of the animals)

Internal parasites (living inside the animal)

Both groups of parasites directly affect herd or flock quality in four ways:

1) infested animals produce weak young,

2) infested animals gain poorly,

3) infested animals develop reduced resistance to disease,

4) infested animals may die if the infestation is severe and treatment is not given.

External Parasites

\section{Biting and Nuisance Flies}

Biting flies, bothersome to livestock in Montana, include stable flies, deer flies, mosquitoes and black flies. The house fly and face fly are examples of nuisance flies. They are irritating even though they do not bite and draw blood. Both biting and nuisance flies affect livestock production and performance by hindering grazing and resting. Additionally, many flies transmit diseases. All biting flies and nuisance 
flies undergo complete metamorphosis. Their life cycle involves four stages: 1) egg, 2) larva, 3) pupa, 4) adult (see Figure 1).

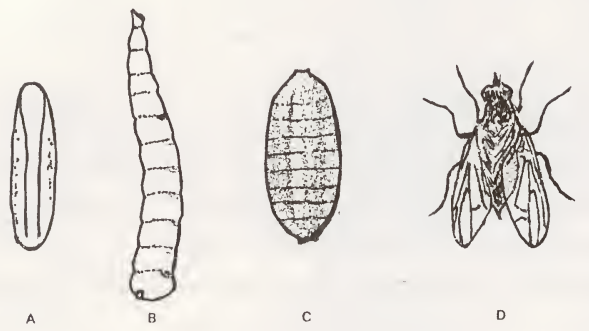

Figure 1. Life stages of a fly. A. egg, B. larva, C. pupa D. adult.

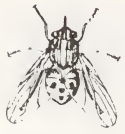

The stable fly, Stomoxys calcitrans, looks much like a house fly except for its more robust body and a prominent beak (proboscis). Both males and females of the stable fly may pierce the skin with the proboscis and suck blood.

Eggs of the stable fly are deposited in wet and decaying vegetation. Piles of grass clippings, hay contaminated with manure and urine, and wet feed are particularly good sites for development of stable fly larvae. In areas where bodies of water occur, stable flies may be particularly abundant because piles of decaying "seaweed" provide a good egg laying site. 
Within five days after egg hatching, the larva pass through three instars (growth stages). Following the larval stage, a pupal stage is formed. In a period of one to two weeks, an adult fly emerges from the pupal case. Because of rapid development from egg to adult, stable flies can produce several generations per season. Stable flies are found indoors as well as outdoors.

Adult stable flies are fierce biters and will attack man as well as domestic animals. Stable flies are not known as vectors of human disease but can transmit several domestic animal diseases.

\section{Control}

The control of stable flies relies in large part on the elimination of breeding sites whenever possible. Spreading of manure to aid in drying is helpful. Other control methods which may be used in combination include: 1) treatment of breeding sites; 2) application of residual insecticides to buildings, sheds, corrals, ets. where flies rest; 3) application of insecticides to animals.

A wide variety of insecticides are registered for use as space or residual wall sprays:

Ravap $1.25 \%$ or $2.50 \%$

Ciovap 1\%

Dibrom $0.3 \%$

Dimethoate $1 \%$

Ciodrin $1 \%$

Vapona $0.5 \%$

Rabon 1-2\%

Ronnel (Korlan) 1\%

malathion $1 \%$

pyrethrins $0.1 \%-0.2 \%$

with synergist 
The above products may be applied in dairy barns. In addition, toxaphene 1-2\% and Baytex $0.72-1.5 \%$ may be used outside barns other than dairy. Malathion ULV may be applied to beef cattle holding pens and feed lots for general fly control.

Products registered for treatment of fly larvae in dumps, manure, etc. include:

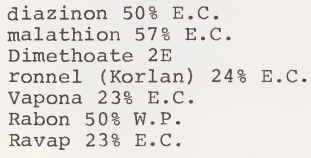

Insecticide labels should be strictly adhered to. Follow label directions concerning rates, registered treatment sites and restrictions.

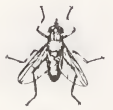

$$
\begin{aligned}
& \text { The horn fly, Haemotobia irritans (L.), is a } \\
& \text { common irritating fly pest of western range and } \\
& \text { pasture cattle. Population development peaks }
\end{aligned}
$$
in June with adult flies abundant during July, August and September.

The adult horn fly looks very much like a miniature stable fly. Both sexes have beaks which they utilize to obtain blood meals. Horn flies may develop very large populations (thousands of flies per animal) on a preferred host. Horn flies have been reported as pests of sheep and horses, but their primary target appears to be cattle. 
Unlike other flies affecting livestock, horn flies stay with the cattle and leave only to visit fresh dung piles to lay eggs. Horn fly larvae develop to pupae within the manure over a two week period (Figure 2). There may be several overlapping generations each summer. Horn flies overwinter as larvae or pupae beneath cattle droppings, while adult flies spend the majority of their life on the animal. They feed only at certain periods of the day.

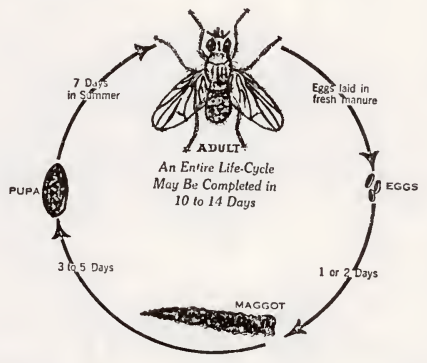

Figure 2. Life cycle of a horn fly.

\section{Control}

Treatment of cattle for horn fly control includes general sanitation around feed lots, holding pens and barns. Under range or pasture conditions, spraying or dipping cattle or the use of dust bags and backrubbers are satisfactory methods of fly reduction.

Materials currently registered for horn fly control are listed next under the appropriate treatment method. Refer 
to product labels for specific rates, application instructions and restrictions.

Applied as a Spray

Ciovap 0.5 \%

pyrethrins

Vapona

nethoxychlor $0.5 \%$

toxaphene $0.5 \%$

malathion $0.5 \%$

ronnel (Korlan) $0.5 \%$

Co-Ral $0.6 \%$

Rabon $0.35 \%$

Ruelene $0.375 \%$

Delnav $0.15 \%$

Ravap 0.45 \%

Prolate (GX 118) $0.25 \%$

$\underset{\text { Dairy }}{\text { and }}$ " Beef Cattle

" " "

Beef Cattle only

" " " "

11

$\begin{array}{lll}11 & \\ 11 & \text { " }\end{array}$

11 1

"

" 11

" $"$

" "

Applied in Feed

Rabon - oral larvicide Dairy and Beef Cattle Ronnel 5.5\% block, granular Beef Cattle only or mineral

Applied as Dust

Co-Ral 1\% Dust

nalathion $4-5 \%$ Dust

miethoxychlor $3 \%$ Dust

$\begin{array}{cccc}\text { Dairy and } & \text { Beef } & \text { Cattle } \\ \text { " } & \text { " } & \text { " } & \text { " }\end{array}$

Applied as Backrubber or Pour-on methoxychlor $50 \%$ W.P. Ciovap 18

Co-RaI $1 \%$ in oil

Delnav $0.15 \%-1.5 \%$

Ravap $1.25 \%$

toxaphene $8 \%$ in oil

ronnel (Korlan) 1\% in oil

Dairy and Beef Cattle

Beef Cattle only

" " " "

" "

" "

Horse and deer flies belong to the same insect family and have similar life histories. The deer flies are about the size of house flies and frequently have colored patterns on their wings. Horse flies are larger and darker in color (see Figure 3) . 


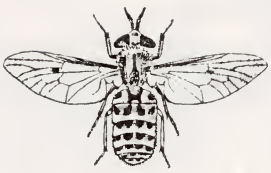

A.

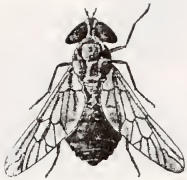

B.

Figure 3. A. Deer fly $0.4-0.5^{\prime \prime}$

B. Black Horse fly $0.8-1.1^{\prime \prime}$

Many species have been described; however, only one or two may be dominant in a particular region. Generally, the adult flies of different species appear in peak numbers at certain times of the season. The common black horse fly, Tabanus atratus Fabricius, may be present from June to September while the deer fly, Chrysops sp. is usually prominent three or four weeks in late June and July.

The flies generally lay their eggs near damp or wet soil of streams, marshes, lakes or ponds. After a short incubation period of approximately one week, larvae hatch and develop in the soil. Later in the season, the full grown larvae migrate to drier soil. Each forms a pupal case from which an adult fly emerges in a few weeks.

Only the female horse fly and deer fly attack animals. The bite is extremely painful and causes the flow of blood, much of which is not ingested by the fly. Frequently clusters of house flies, which cannot draw blood themselves, are seen around pools of blood formed by the feeding of horse flies. Control

Horse and deer flies are difficult to control. Elimination of breeding sites is generally not practical in most 
areas. Providing daytime shelters for animals and pasturing in the evening can prevent attack since the flies do not bite at night. A repellent spray of $9.1 \%$ pyrethrin and $1.0 \%$ piperony 1 butoxide has been shown to give protection for one to three days. General fly control measures aimed at other species may be somewhat effective in repelling or reducing horse and deer flies.

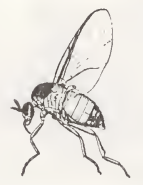

Black flies are among the smallest of the biting flies attacking livestock. They are frequently called buffalo gnats because of their "humped back" appearance. Black fly may be a misnomer because these insects are frequently light brown or greenish in color.

Larval and pupal black flies spend their lives in rivers or streams where running water provides sufficient aeration. Several hundred eggs may be deposited on or in the water by the adult female. These aquatic stages are attached to objects such as stones, logs, and submerged vegetation. The length of the life stages vary considerably with species. The adult flies that emerge from the pupal cases are capable of moving great distances from the streams of their origin. Females are blood suckers and may occur in large swarms.

Black flies feed either on exposed areas of skin or deep within the hair coat where they must bury themselves in order to obtain a blood meal. Black flies bite only in the daytime. The reaction to bites may be quite severe. Some of the most vicious biters, even though they may be extremely abundant, 
appear to ignore man completely in favor of horses and cattle. Control

Control of black flies is quite difficult. There are currently no products registered specifically for black fly control either as a larvacide or adulticide. Sometimes treatments aimed at mosquito reduction may provide some reduction of black flies.

\section{Mosquitoes of 43 species distributed among 6 genera} occur in Montana. The most common mosquitoes affecting livestock are members of the genus Aedes. Most control operations are directed at this group. The other genera that are bothersome to livestock are Culex and Culiseta. The mosquite species Culex tarsalis is of public health importance in Montana because it is the principle vector of human and equine encephalitis.

All mosquito species have four distinct stages in their life cycle: egg, larva (wiggler), pupa (tumbler), and adult.
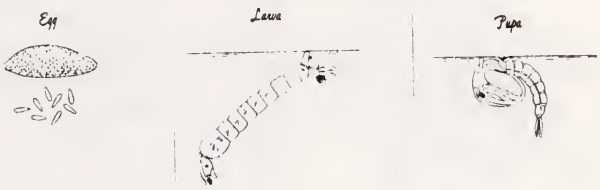

Figure 4. Life stages of Aedes mosquito.

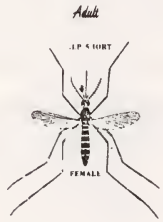


The first three stages require water for development. Eggs of all species (except Aedes) and all larvae and pupae will die if they are out of water. For this reason, source reduction (draining, ditching, filling) is effective in controlling mosquitoes.

Aedes are a temporary water mosquito, implying that they are produced in water which is retained on the surface for a minimum of about seven days but which disappears during the course of the season. They may also be found in permanent or semi-permanent bodies of water which have periodic fluctuations in water levels. Eggs of some Aedes species retain the ability to hatch if flooded even after a period of five years on dry land. Hence, two or three dry years do not solve most Aedes mosquito problems. Aedes overwinter in the egg stage.

Eggs of the Culex and Culiseta species are laid in rafts on the surface of permanent or semi-permanent bodies of water. Eggs of these mosquitoes must have water to remain viable.

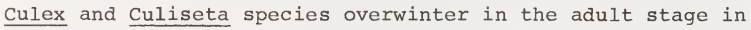
sheltered areas. Since there is usually a high mortality of adults of these species during the winter, population of these species do not build up until later in the season. There may be several generations each year.

\section{Control}

Since mosquitoes do require standing water for reproduction, proper water management along irrigation systems and elimination of standing water can be quite beneficial. In 
additition to source reduction, biological control of mosquito larvae using the minnow, Gambusia affinis, has proven successful in many permanent pond situations.

Insecticide treatments are recommended only as supplemental to source reduction and biological control. Mosquito control chemicals are designated either Adulticides or Larvacides. Adulticides are available as "Liquid Concentrates" for use in "Ultra Low Volume" application or "Emulsifiable Concentrates" for use in standard ground based equipment. Both forms can be diluted with oil for use in thermal fog generators. Larvacides are available as "Liquid Concentrates", "Emulsifiable Concentrates" or "Granules".

Following is a listing of currently registered products. Consult the product label for specific application information. For more information concerning mosquito control, contact the Food and Consumer Safety Bureau of the Montana Department of Health and Environmental Sciences.

Larvacide

Abate

Altosid SR-10 DDVP (Vapona) dursban fenthion (Baytex) malathion
Adulticide

Baygon

DDVP (Vapona)

Dursban Fenthion (Baytex)

Malathion Methoxychlor Naled (Dibrum) Pyrethrins 


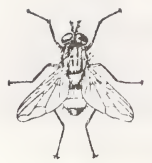

Both face flies and house flies may be abundant on cattle. Face flies are also pests of horses. Face flies look very much like large house flies and will be found clustered around the eyes, nose, and general face region of the host. Horses do not like this pestering and fight them continuously. Cattle are more tolerant of them. Like house flies, they do not bite but lap up milk and saliva from nursing calves' faces, blood from wounds and the secretions from the host's eyes. The action of their rather rough mouthparts on the tender membranes bordering cattle's eyes cause rather severe irritation to the eyes with considerable reddening and excessive watering. In addition, they may transmit pink eye and other eye disorders from one cow to another.

The face $f l y$ is a strong flier and can travel several miles. Individual face flies do not remain with cattle and horses at all times and do not enter darkened stables. The adult face $f l y$ passes the winter in the adult stage within shelters and is frequently a household pest in the spring when the flies emerge from their indoor hibernation quarters. Several generations can be produced in one season.

The house fly is a pest closely associated with man's activities. It is able to utilize all sorts of excrement and fermenting organic material such as that found in garbage dumps as a larval medium. It is considered primarily a pest of livestock in and around buildings and can be very annoying 
when present in great numbers.

\section{Control}

Control measures for face flies are effective primarily on dairy cattle. Insecticides are available as spray-on, dust or backrubber application. Refer to the product label for specific application instructions. The following compounds are currently registered:

Ciovap $0.5 \%-1 \%$ - spray or backrubber Rabon 3\% - dust Rabon - oral larvacide Vapona $1 \%$ - spray Co-Ral $1 \%$ - in oil or dust

Dairy cattle treatments are usually not suited to beef cattle. General dust bag and backrubber treatment may afford some control. Malathion ULV application by aircraft has protected small herds in confined pastures for several days.

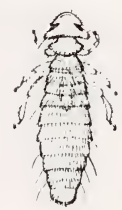

\section{Lice}

Various species of biting lice (order Mallophaga) and sucking lice (order Anoplura) infest domestic animals. Anoplura are blood sucking lice with mouthparts reduced to stylets which are retracted within the body when not in use. Mallophaga have obvious chewing mandibles and feed on epidermal products as well as blood and exudates when available.

Four species may be found or cattle, two on horses, one on swine, two on sheep, and several species on cats and dogs. Itching, restlessness, and loss of hair may be signs of lousi- 
ness and careful exanination of the skin by parting the hair on various parts of the bociy will reveal their presence. Iouse eggs are glued on to hairs and are pale, translucent and oblong. The young closely resemble the adults except for their smaller size. Lice in both groups complete their entire life cycle on the host animals. About three to four weeks is required for complete development from egg to adult but this varies with species and climatic conditions.

\section{Control}

Timely treatment of lice-infested animals (two or three times at two week intervals) will usually eliminate the problem. Currently registered products available for louse control on cattle are listed below. Refer to product labels for specific application instructions and restrictions.

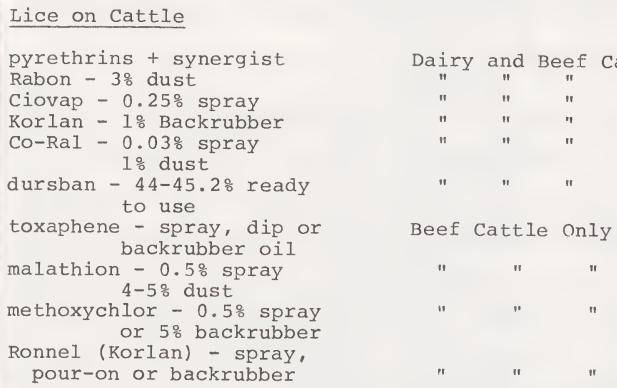

Beef cattle only 


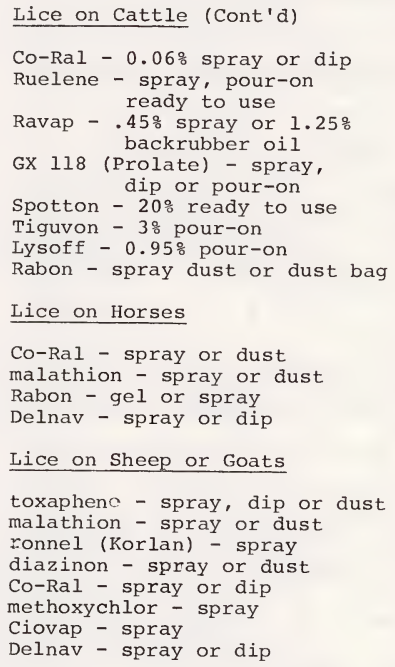

I.ice on Swine

malathion - spray or dust methoxychlor - spray Co-Ral - spray or dust Ronnel (Korlan)- spray, granules

lindane - spray, dip or dust

Delnav - spray or dip toxaphere - spray, dust or dip

Rabon - spray or dust

Tiguvon - pour-on

Ciovap - spray

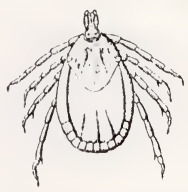

\section{Ticks}

Ticks belong to an order closely related to insects. They are small to minute hardbodied animals that live as ectoparasites on various animals and man. By attaching themselves to the host and sucking blood, they cause annoyance, irritation and loss of vigor. If ticks are present in large numbers, they may cause anemia, depression, and general debilitation. Some ticks cause paralysis from which the animal 
usually recovers rapidly following effective treatment or removal of the ticks by hand. Tularemia and Rocky Mountain spotted fever are transmitted from one animal to another through the bites of infected ticks.

Two species of ticks are common in Montana: Dermacentor andersoni (Rocky Mountain woodtick) and D. albipictus (winter tick or elk tick). Several other species may occassionally be encountered. The Rocky Mountain woodtick is a three-host tick. The young feed on rodents and the adults feed on domestic livestock and larger wild animals. It is most commonly seen on animals in late spring and summer. The winter tick is a one-host tick. The young attach themselves to deer, moose, elk, horses, and cattle in late fall and are generally most noticeable on these animals in late winter or very early spring. Ticks feed on blood and when fully engorged, the adult females may be as large as a small pea. At this stage, they drop to the ground, lay hundreds of eggs under debris on the surface of the soil, and then die. Eggs hatch in two to several weeks; the young climb into vegetation to wait the passage of a suitable host animal. When one brushes against their perch, they "seize" the host and begin their parasitic life.

\section{Control}

Natural control of tick populations occurs with fluctuations in climatic conditions. When treatment of cattle becomes necessary, there are several chemicals available that can be applied as a spray or dip. Refer to the product label for 
rates, specific application instructions and restrictions regarding treatment of dairy and beef animals.

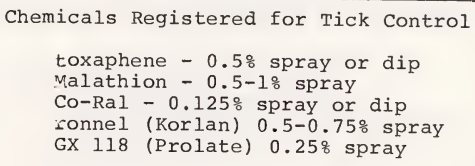

Ear Tick

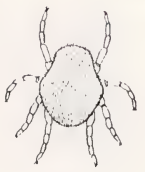

Unlike the ticks described above, the ear tick, Octobius megnini (Duges), is considered a softbacked tick. The life cycle is similar to other ticks. The nymphs and larvae are covered with spines. It attaches deep in the ears of cattle, sheep, horses and many other animals. The irritating bites within the ear often become infected with bacteria resulting in a condition called "ear canker". Affected animals often scratch the ears producing wounds that attract screwworm flies in southern climates.

\section{Control}

A spray of $0.5 \%$ malathion, ronnel (Korlan) 5\% liquid pour-on, or Co-Ral $5 \%$ dust applied within the infected ear are effective. Nahere strictly to label directions.

\section{Mange Mites}

Several different mite species produce a disease of various domestic animals known as mange. The type of mange 
is named after the mite causing it, e.g. sarcoptic mange, psoroptic mange, and chorioptic mange which are caused by Sarcoptes, Psoroptes, and Chorioptes mites, respectively.

All three mite species are related to and have developmental stages similar to those of ticks, i.e. eggs, sixlegged larvae, eight-legged nymphs and adults. Mites are nearly microscopic in size and barely visible to the naked eye. The symptoms of the disease may consist of blisters and small bumps in the skin, swelling and inflammation of the skin, scabs which consist of serum and scurf, and in advanced cases, a dry, leathery skin condition may follow. In the case of sheep, indications of the disease are usually first noticed by the disturbed appearance of the wool. Where mites are active, the wool looks uneven, picked, and thin.

Positive diagnosis of mange is made by examining for mites. Scrape lesions with a knife, place them on a black cloth, warm and observe for mites. They are smal1--about 1/40th of an inch long--but they can be seen by the unaided eye. The body is white or light yellow.

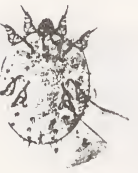

Adult sarcoptic mites burrow within the skin of the host and cause severe irritation. Eggs are laid within the burrows. Development of the mite from egg to reproductive adult takes approximately two weeks. Lesions usually, but not always, first appear on the head, neck and shoulders, then spread to other parts of the body. 
As the host scratches to relieve irritaion, blisters and small bumps or ridges develop. Further scratching causes the blisters to break, forming scabs. In advanced cases, the mites become inactive and the affected skin becomes dry, wrinkled and hairless and remains so for some time.

Sarcoptic mange of horses can be transmitted to man where it causes transitory itch.

Psoroptic and chorioptic mange have many similarities. Mite life cycles take about two weeks. The habits differ from those of sarcoptic mites, however. Psoroptic and chorioptic mites do not burrow in the skin of the host. Instead, by pricking the skin to feed, they cause serum to ooze from the wounds. Accumulation of serum causes the formation of scabs which, in the case of Psoroptes, start on the hairier parts of the body. Psoroptes infestations eventually may involve large areas of skin all over the body, whereas Chorioptes infestations start in and are restricted to the feet and lower hind legs.

Chorioptic mange has been found on practically all types of domesticated animals including cattle, sheep and horses. Cattle are probably the important host species.

Psoroptes mange is often called "scab", a disease common to many types of livestock. It is a highly contagious form of mange.

Mange mites are transmitted by contact with infested animals. Populations are generally greatest in the winter when host hair coats are long and animals are frequently crowded together. 


\section{Control}

Treatment of mites is best achieved by dipping or spraying infested animals. Special formulations of toxaphene are recommended for cattle and sheep. Lindane as a spray or dip, malathion as a spray and toxaphene as a spray or dip are registered for treatment of mange on swine. Refer to specific product labels for application instructions and restrictions. Consult the Cooperative Extension Livestock Specialist for further information regarding mite control.

\section{Sheep Tick}

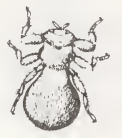

The sheep tick, Melophagus ovinus (L.), is not a tick but a small wingless red-brown fly. Adults are present throughout the year sucking the blood of sheep and goats. Ked feeding results in skin irritation which causes the sheep to rub and bite at the fleece. The fleece becomes thin, ragged and dirty. Infested sheep may lose vitality and become thriftless. The female does not lay eggs but gives birth to live larvae which are cemented to the wool. The larva pupates within 12 hours and after a period of about three weeks, the adults emerge and mate. There are several generations a year.

\section{Control}

Control of sheep keds is accomplished by dipping, spraying or dusting infected animals. Dusting at shearing time may be the most convenient. Compounds currently registered are listed next. Refer to specific product labels for application instructions and restrictions. 


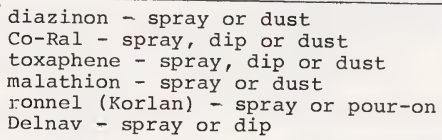

\section{Internal Parasites}

\section{Cattle Grubs}

There are two species of cattle grubs in Montana, the common cattle grub, Hypoderma lineatum, which is the predominant species and the northern cattle grub, Hypoderma bovis. Losses due to these insects have been estimated at $\$ 160$ million annually. Cattle fear the adult flies and become very agitated at their presence. They may run wildly, injuring themselves. There is often marked reduction in milk flow and weight gain. Skin penetration is irritating to the animal and damages the flesh and hide.

Both fly species prefer to lay eggs on the lower parts of the body of cattle. The eggs hatch in three or four days into larvae which burrow into the skin of the animal (Figure 5).
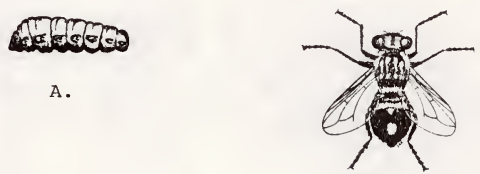

3.

Figure 5. Common cattle grub, Hypoderma lineatum.

A. larva. B. adult. 
The larvae, over a period of six to eight months, make their way through the body until they reach the gullet, in the case of the common cattle grub, or the spinal canal, in the case of the northern cattle grub. The grubs stay at these locations for up to eight months, then migrate to the muscles of the back, cut breathing holes in the hide and grow to full size. After reaching full growth, (35-90 days for common and 55-100 days for northern) the larva drops from the back and forms a pupa on the ground. Adult flies emerge from the pupae and are present May to July. These flies mate, then seek cattle for egg-laying and the beginning of a new cycle, usually within one hour of emerging from the pupa.

\section{Control}

Control of cattle grubs consists of treating the backs of infested cattle when the grubs are in this region. Dipping of cattle is also effective. Below are listed the currently registered products for grub control. Refer to the specific labels for application instructions and rates. Carefully heed the label differences for dairy and beef cattle.

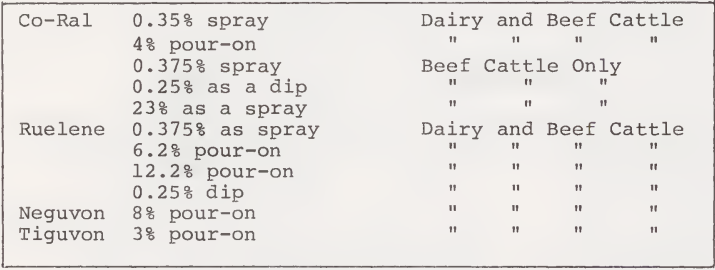





\section{CHAPTER III}

\section{INSECTS AND RELATED PESTS OF POULTRY}

Control of Poultry Pests Through Management

Poultry may be attacked by a wide variety of pests. A poultry pest management program should strive to reduce flies and similar nuisance pests as well as specific poultry parasites. Neglected pest management can result in a low vigor, poor quality flock.

Control of filth-breeding flies is as important to poultry production as it is to livestock production. Insecticidal control of these pests is usually not totally effective. Reduction of breeding sites is an essential first step. This can be accomplished in and around poultry production facilities by :

1) open building construction to provide good air circulation and sunlight for rapid drying of droppings.

2) sound construction of plumbing and watering equipment along with adequate drainage to prevent wetting of organic waste.

3) well maintained litter floor, with rapid turnover of droppings in the ary litter.

4) laying flocks housed in single bird, wire floored cages rather than group cages.

5) proper disposal of manure compost either in flytight containers, or in tight piles with insecticidal treatment of surface.

6) weekly spreading of manure in thin layers over a field.

7) frequent removal of manure compost to a sanitary landfill or other suitable disposal site away from the farm. 
Recent advances in poultry production may not have been made with pest control in mind. An increased awareness of certain management techniques can be beneficial. Below are listed several precautions which can minimize the introduction and spread of poultry pests.

1) Isolation of replacement birds for a short time can free them of some temporary pests that will leave the birds. Fowl tick larvae, for example, will leave the bird within a ten day period. Hot water or steam scalding or chemical treatment of the holding crates will prevent spread of the parasites.

2) Treatment of replacement birds with a suitable insecticide before introduction into the flock will eliminate many semi-permanent or permanent parasites such as lice and mites.

3) Before restocking of pens and housing, clean the facilities thoroughly. If ticks, mites or fleas are known to be present, treat the housing with an approved insecticide. Even facilities left vacant for months may still contain active parasites.

4) Be wary of used equipment and cages. Pests can easily be introduced into the flock through contaminated equipment or even on the clothing of workers or farm visitors.

5) Assure that housing is tightly constructed, free from cracks or loose boards, to prevent build up of those pests seeking shelter. Construct roosts that 
easily disassemble for cleaning and treatment. Do not allow birds to roost on sheds or in trees.

6) If chiggers are a problem, restrict free range of birds during the months of heavy mite populations.

7) Try to discourage wild birds from nesting in and around poultry buildings. Remove their nests and screen them out.

\section{Representative Poultry Pests and Their Control}

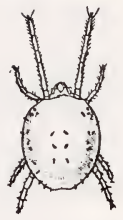

There are five important species of mites which attack poultry. Their feeding activity results in retarded growth, lower vitality, damage to plumage, and a reduction in egg production. Severe infestations result in death.

Chicken mites (roost mites) attack poultry by attaching themselves to the chicken during the night and sucking blood. They retreat to cracks and crevices in poultry houses during the days. The female mite requires a blood meal before laying her eggs. Since only 10 days are required for mites to mature, several generations a month are produced during the summer.

Northern fowl mites look much like chicken mites but stay on the fowl constantly. They are found congregated near the vent, tail and neck. Feeding results in soiled feathers and formation of scabs on the skin of infested fowl.

Scaly-leg mites attach by burrowing under the sides of the fowl's feet and lower legs resulting in itching and irritation. Untreated fowl will develop distorted feet and legs 
and some of the terminal joints of the feet may be lost.

Depluming mites attack fowl at the base of the feathers where they burrow into the skin. Attempting to relieve the irritation, the bird pulls out its feathers until it is nearly naked.

Chiggers (red mites) attack poultry and man as well. Poultry become infested as the mites attach themselves in clusters to the skin under the wings and on the back and neck. Young fowl are greatly affected. They become droopy, emaciated and refuse to eat. Abscesses and extensive areas of inflammation commonly occur.

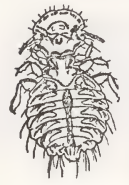

Poultry lice are often of primary concern to the poultry producers. A dozen or more species attack chickens while others attack turkeys, ducks, geese, guineas and pigeons. Lice infected birds appear droopy, lack appetite and may fail to lay eggs. Poultry lice live on the host year around but are usually more abundant during the summer. Lice eggs adhere to the feathers. The young nymphs complete several molts and become adults within a few weeks. Many overlapping generations can occur.

\section{Control}

Lice and mites can be controlled by similar means. Some products are designed for application directly to the bird while others are applied to litter, housing or roosts. Products currently available are listed under their respective application site. Consult the product label for specific 
application instructions and restrictions.

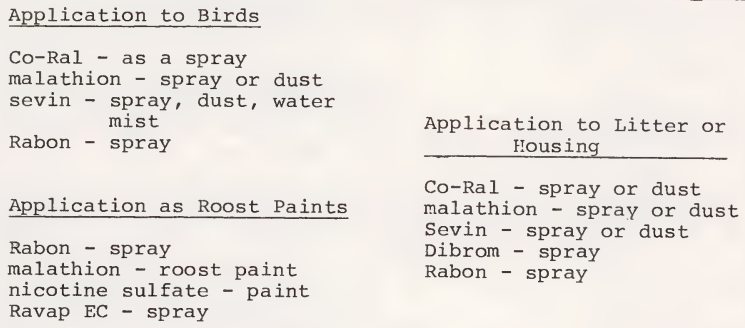

Application to Litter or Housing

Co-Ral - spray or dust malathion - spray or dust Sevin - spray or dust Dibrom - spray Rabon - spray 
$+$ 


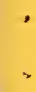

.

. 
50 copies of this public document were published at an estimated cost of $\$ 2.22$ per copy, for a total cost of $\$ 110.93$, which includes $\$ 85.93$ for printing and $\$ 25.00$ for distribution. 